\title{
A LEITURA E A ESCRITA PARA A EDUCAÇÃO INFANTIL
}

\author{
Célia de Siena Rodrigues de Siqueira ${ }^{1}$ \\ Claudia Dias Barbosa ${ }^{2}$ \\ Cleide Aparecida Pereira Cirino ${ }^{3}$ \\ Joice Ferreira de Oliveira Alencar Cardoso ${ }^{4}$ \\ Layra Milena da Silva Suquere 5 \\ Verônica Delgado do Nascimento Barbosa ${ }^{6}$
}

RESUMO: Este artigo tem como objetivo analisar a importância da leitura e da escrita para o desenvolvimento de crianças na educação infantil, a fim de promover maior interação com o mundo literário e poder realizar ações ativas nesse processo. Portanto, é necessário pensar e planejar este espaço e proporcionar momentos de ludicidade, o que ajuda cada participante a imaginar ativamente, transformar idéias em ações concretas, e utilizar materiais e recursos existentes para obter um desenvolvimento integral. Os educadores devem se inspirar a receber uma formação contínua para atuar na área, com o objetivo de promover um momento de diversão e conhecimento, que auxilie no desenvolvimento humano de todos.

Palavras-chave: Educação Infantil. Formação. Leitura e escrita.

ABSTRACT: This article aims to analyze the importance of reading and writing for the development of children in early childhood education, in order to promote greater interaction with the literary world and be able to take active actions in this process. Therefore, it is necessary to think and plan this space and provide moments of playfulness, which helps each participant to actively imagine, transform ideas into concrete actions, and use existing materials and resources to achieve full development. Educators should be inspired to receive ongoing training to work in the area, with the objective of promoting a moment of fun and knowledge, which helps in the human development of everyone.

Keywords: Early Childhood Education. Formation. Reading and writing.

\footnotetext{
${ }^{I}$ Graduada em Pedagogia pela Faculdade Afirmativo, Especialista em Educação Infantil e Especial Faculdades Integradas Mato-Grossenses de Ciências Sociais e Humanas - Mantidas pelo Instituto Cuiabano de Educação - ICE.

${ }^{2}$ Graduada em Pedagogia pela Universidade de Cuiabá - UNIC.

3 Graduada em Pedagogia pela Universidade do Estado de Mato Grosso - UNEMAT, Especialista em Psicopedagogia Clínica e Institucional pelo Instituto Superior de Educação IBITURUNA.

${ }_{4}$ Graduada em Pedagogia pela Universidade de Cuiabá - UNIC, Especialista em Alfabetização e Letramento pelo Centro Universitário Leonardo da Vinci - UNIASSELVI.

5 Graduada em Pedagogia pela Faculdades Integradas Mato-Grossenses de Ciências Sociais e Humanas Mantidas pelo Instituto Cuiabano de Educação - ICE, Especialista em Educação Especial e Inclusão com Ênfase em AEE pelas Faculdades Integradas de Várzea Grande - FIAVEC.

${ }^{6}$ Graduada em Pedagogia pelo Centro Universitário Cândido Rondon - UNIRODON, Especialista em Educação Infantil na Faculdades Integradas de Várzea Grande - FIAVEC.
} 


\section{INTRODUÇÃO}

$\mathrm{Na}$ primeira infância, jogos, linguagem e contação de histórias estão intimamente ligados. Observou-se que a história pode fazer parte da vida de bebês e crianças, portanto, quando os educadores leem para eles, abrem caminho para interações surpreendentes no mundo da leitura e da escrita.

Os adultos que leem para as crianças desde pequenas, permitindo-lhes entrar em contato com a linguagem imaginária, proporcionando viagens, despertando a curiosidade e apresentando novos conhecimentos, que lhes permitem criar outras realidades. Dessa forma, é necessário considerar o espaço e o tempo para que elas tenham a chance deixar a magia acontecer.

Sobre esse momento de pensar e planejar, os educadores pesquisam, pensam e repensam suas estratégias de ensino, colocam em prática todos os conhecimentos adquiridos e transformam as pesquisas realizadas em realidades concretas.

Devemos considerar que o momento de contar histórias e ler, deve ser o momento em que as crianças são expostas ao mundo da linguagem. É importante estabelecer um vínculo afetivo para fortalecer o método do tipo narrativo selecionado.

O educador deve planejar momentos relevantes, pois possui um domínio maior neste campo da linguagem e necessita promover o estabelecimento de um espaço de comunicação com a classe. As crianças aprendem em um ambiente material e social interativo e, no caso do aprendizado da linguagem falada e escrita, não há exceção: as crianças aprendem por meio da comunicação social gerada em diferentes situações de interação, de diferentes faixas etárias.

A aprendizagem da língua falada e escrita permite que as crianças tenham acesso e participem de diversas atividades sociais, o que favorece a sua integração cultural. Por meio da linguagem, ela pode se comunicar, se expressar e expandir seus conhecimentos.

Através da Educação Infantil, esse tipo de experiência acontece todos os dias, e é proporcionado a um mundo lúdico que lhes permite entrar em contato com a escrita de uma forma mais interessante.

As crianças aprendem de forma inconsciente e, por fim, demonstram isso por meio de suas atitudes e comportamentos. Os bebês, por outra perspectiva, ficam muito surpresos, ao 
colocarem os livros na sala, eles vão observar e analisar as imagens, cores, texturas e tudo que o objeto possa representar naquele momento.

No processo de leitura compartilhada, eles podem associar sons a imagens, como animais, e alguns ainda podem sentar e ouvir histórias criadas por educadores durante muito tempo.

Portanto, podemos avaliar a importância de tal acessibilidade. Ainda antes dos primeiros anos do ensino fundamental, esse tipo de coleta de informações vem sendo implantada e cultivada na educação infantil, que respeita as etapas de desenvolvimento de bebês e crianças, mas não deixa de lado a formação humana.

\section{DESENVOLVIMENTO}

2.I Bebês e crianças como objetos de ação e reação

Os estágios de desenvolvimento de bebês e crianças sempre foram objeto de pesquisa. Dadas as opiniões defendidas por volta do século XV, eles eram considerados adultos em miniatura (uma visão centrada no adulto). Desprezados por todos os meios, eram deixados em locais inadequados, com o único propósito de ajudar seus responsáveis a poderem trabalhar, de forma que as pessoas nessa idade eram invisíveis para a sociedade como um todo.

Apenas por volta do século XX, o estudo do desenvolvimento infantil ganhou alguns pesquisadores famosos, como Freud. S. (1856 - 1939) e logo após Vygotsky. L. (1896-1934) com a ZPD - Zona do Desenvolvimento Proximal, Piaget. J. (I896-1980) e a teoria dos estágios de desenvolvimento, Walton. H. (1879-1962) em sua teoria do brincar, buscando um conhecimento mais aprofundado dessa faixa etária e suas singularidades, e de fato crendo no potencial de aprendizagem de bebês e crianças.

Pesquisas aprofundadas, mesmo que realizadas recentemente, há cerca de 20 anos, mostraram que bebês desde o útero materno já possuem uma herança genética que organiza todo o cérebro, desde aproximadamente a segunda semana de gravidez, ou seja, não há como continuar o pensamento deles serem uma "tábula rasa" porque são capazes de adquirir conhecimento antes mesmo de virem realmente a este mundo. Sendo assim, quando esse momento ocorre de fato, os bebês serão estimulados mentalmente pelo ambiente em que viverem, o que também pode ser moldado por adultos, mas não em sua capacidade total em face das atividades complexas a que estão expostos no dia a dia. 
Tudo o que está próximo ao bebê contribui para o desenvolvimento do seu cérebro, pois não é formado apenas por herança genética, mas também pelos efeitos de influência que recebe no ambiente ao qual pertence. Com isso, alguns paradigmas relacionados ao desenvolvimento dos bebês são rompidos e, às vezes, essa aparência frágil é deixada de lado, podendo nesses momentos serem considerados pessoas com muitas potencialidades em seus movimentos e exercícios de locomoção.

Portanto, todo o ambiente precisa ser cuidadosamente pensado e planejado para atender todas as necessidades dos bebês e crianças da instituição. $O$ meio precisa inspirar novas conquistas e descobertas, é nele que as crianças podem expandir todas as suas atividades e ter materiais que promovam todo o nível de conhecimento. Os materiais em sala de aula são uma escolha importante, pois à medida que os bebês adquirem novas habilidades motoras, é necessário reinterpretar o espaço de aprendizagem para ampliar o repertório da brincadeira, promovendo a importância e o respeito de cada bebê e seu processo de desenvolvimento individual.

Os bebês, por não possuírem uma linguagem falada definida, possuem o próprio corpo como meio de expressão, o que inclui expressar sua satisfação e insatisfação com o momento que vivenciam. Algumas formas de expressar o choro podem revelar que o bebê sente dor, está sujo, ou com fome. Caberá ao educador compreender o que o bebê quer dizer. Essa observação percorrerá todo o processo de desenvolvimento do bebê até que ele consiga expressá-lo verbalmente.

A questão é "bebê participa de roda de leitura?" e a resposta é sim. Nesse estágio, os bebês estão observando os vários modelos de linguagem que os adultos à sua volta apresentam espontaneamente a eles todos os dias. Devemos planejar deliberadamente as atividades de rodas de histórias para poder estender esses modelos de comunicação de um modo lúdico. Os olhares focados, os pequenos gestos e até os sorrisos no evento apresentam a participação de todos nesses momentos, e cada um participa do seu jeito.

Histórias intencionadas aos bebês e crianças promovem a vivência de mundos ficcionais, estimulam a imaginação e o lúdico e, assim, conquistam expressões que podem surpreender qualquer pessoa. $\mathrm{O}$ momento da leitura deve proporcionar a alegria de quem escuta uma história incrível. Ante ao tom da voz e a explicação, tornam esse momento mágico e realmente atraem a atenção de todos. É desta forma que os bebês expandem seu aprendizado 
da linguagem escrita e ampliam suas fases orais, onde estão todos os dias ouvindo as pessoas falando em seu ambiente.

O indivíduo dessa idade finalmente chega ao mundo da alfabetização, sem a necessidade de realizar atividades que exijam a escrita direta, aprendendo desde muito cedo a associar a imagem ao texto escrito, o que revela a importância da leitura para bebês e crianças.

Por meio da narrativa, o universo é moldado para os pequenos. Como disse Paulo Freire: "a leitura de mundo precede a leitura da palavra" significa que as crianças usam os recursos adquiridos até então para ler o mundo de forma significativa, como ler olhares, rostos, expressões, olfato, tato, usando os cinco sentidos a todos os momentos.

Neste contexto, a percepção correta do mundo circundante pode ser implementada, de modo que possa ser plenamente desenvolvida em diferentes campos como cognição e psicossocial.

É possível passar momentos da história sem exigir muitos recursos. Basta ser criativo e buscar em um ambiente acolhedor. As emoções podem falar por si mesmas. Os materiais não estruturados viram festas nesses momentos e podem acabar até mesmo tomando toda a atenção para si durante a narrativa. Proporcionam uma viagem além do físico espaço, e assim ocorre a mágica.

\subsection{A importância da interatividade para o desenvolvimento da linguagem de bebês e crianças}

Por meio de um diálogo, um círculo de conversa ou um círculo de histórias, que bebês e crianças são introduzidos no mundo da literatura. No entanto, alguns educadores desprezam o trabalho lúdico até nos momentos de cuidados com o corpo, olhares fixos e toques afetuosos. Esses atos cultivam uma parceria e uma autoconfiança que os capacita a se realizarem, para que possam se expressar de uma determinada forma segura e agradável e, de fato, alcançar o que é considerado um desenvolvimento psicossocial positivo, em base da faixa etária e ao grupo que pertencem. Todos os gestos visuais, sonoros e táteis fornecidos pelos educadores podem ser usados também como livros ou espelhos de linguagem.

Portanto, os educadores devem observar com atenção e promover esse contato da forma mais agradável possível, para que hábito de ler ou ouvir histórias não se torne um momento que não faça sentido para elas. Será de grande valia o primeiro contato infantojuvenil, que se baseia nos preceitos da contribuição ativa à interação, todos ilustrando a 
construção e o desenvolvimento da linguagem, através de toda sua trajetória. Existindo apenas algumas mediações adultas nesses momentos.

No entanto, o estudo da psicologia da história cultural, especialmente por Lev S. Vigotski (I896-1934), na antiga União Soviética, e Henri Wallon (I879-1962), na França no início do século $\mathrm{XX}$, que consideram o potencial de bebês e crianças, elucidam sobre o que eles podem fazer, além também de fornecer instruções para o relacionamento entre os adultos e eles.

Os trabalhos desses autores nos ajudam a compreender a qualidade social dos papéis do adulto e a promover a relação entre as crianças e a realidade. Por meio da ação conjunta, eles entram na cultura e desenvolvem o processo de comunicação. No processo, os adultos também sofrem mudanças, apoiando-se na afetividade e expandindo sua experiência.

Vigotski (1989) analisa como as crianças são subjetivamente constituídas em seu meio social. Nesse caso, a formação de si é compreendida no processo de interação e negociação com os "outros". Por meio do trabalho de Vigotski, é possível identificar o "nascimento cultural" de um bebê a partir da matriz biológica (essencialmente corporal) que o constitui.

Bebês e crianças se reconhecem como imagens adultas e vice-versa, eles podem coordenar suas intenções na comunicação. Nesse caso, uma rede de ações que se combinam mutuamente, geralmente sem linguagem, mas que podem mobilizar conexões e produzir sentido. Nessas reuniões, à medida que novos desenvolvimentos ocorrem, as crianças aprendem sobre si mesmas e sobre os outros.

Elas se reconhecem e se distinguem, também aprendem a atribuir emoções, aprendem a estabelecer conexões com diferentes indivíduos de referência, aprendem a se socializar. Essas ações são deliberadamente planejadas pelos educadores para que suas sugestões pedagógicas realmente alcancem os objetivos desejados, e essas atitudes levam a um aprendizado cada vez mais importante.

Segundo Wallon (2008), a primeira fase da vida humana, situada no nascimento e nos primeiros meses de vida, é emocional ou afetiva, guiando a intuição inicial do bebê para com os outros e colocando a sociabilidade em primeiro plano. No próximo momento, já se situa no mundo físico.

Dessa forma, "na medida em que a criança não pode orientar-se senão para o meio humano e técnico do qual dependem sua existência e subsistência, já há o reflexo das relações 
às quais a palavra e o poder de imaginar as coisas servem como instrumento indispensável nas relações humanas" (WALLON, 2008, p. II9).

Isso significa que mesmo sem a capacidade de dominar a expressão, nesses estágios iniciais, as ações sobre o ambiente nunca são puramente processando coisas, mas ocorrem no amplo e diversificado acordo entre movimento e percepção, o que constitui um desenvolvimento em expansão.

Portanto, ao ler livros ou contar histórias a bebês e crianças, você poderá notá-los repetindo sons, observando com atenção e reproduzindo seus movimentos faciais e gestos. Esta é uma oportunidade importante para interagir, compreender nos os outros a experiência emocional e a linguagem.

No contexto da educação infantil, é possível ver o repertório de brincadeiras que compartilhamos com bebês e crianças, principalmente por volta dos dois anos. Quando já não são mais bebês, enriquecem com a existência de bonecos, fantoches e brinquedos. Tudo que favorece o simbólico, a experiência inicial de capacidade representativa, ou seja, "faz-de-conta que $[\ldots]$ ”.

O repertório de imagens que disponibilizamos através da narrativa, história e elementos literários também enriquece as possibilidades de imitação, ficção e ludicidade nas crianças.

\subsection{Formação do educador}

Tudo deve ser planejado com antecedência, planejado com calma para não haver improvisos. Ele pode até acontecer, mas no momento do conto de histórias, o uso da imaginação está a todo vapor. Hoje em dia, a formação do educador é muito importante para a implementação desses projetos, ele é quem prepara tudo, estuda as possibilidades e coloca em prática todos os saberes.

A exploração incessante dos cursos profissionalizantes é essencial, pois expande significativamente a atuação no centro de educação infantil, oferece o maior número de oportunidades de aprendizagem para esses pequenos e pode fazer todas as mudanças na formação humana das crianças.

A escolha da história deve acontecer com uma certa intenção do educador. Se ele quiser usar adereços que promovam a viagem do imaginário, deve fazer deste momento um 
momento inesquecível, para que a oportunidade de ler e escrever aconteça sem pressão e seja de grande significado, para bebês e crianças.

O que precisa ser considerado não é a quantidade de coisas, mas a qualidade dos materiais apresentados. Saber que uma pena pode se transformar em um pássaro está além dessa sugestão, mesmo utilizando brinquedos estruturados e não estruturados. Para as crianças conseguirem imaginar e construir uma narrativa.

Portanto, considerar a formação de educadores que atuam na educação infantil, compreendendo a importância dessa etapa de ensino, é também reconhecer que a criança é o principal indivíduo interagindo com signos e objetos simbólicos, podendo sentir-se parte da cultura marcada pela linguagem escrita.

Os bebês nos ajudam a perceber o que Paulo Freire nos ensinou: ler o mundo antes de ler as palavras, ou seja, todos devem ser estimulados a descobrir coisas novas, o mundo em que vivem pode e deve se apresentar de diferentes maneiras, para que de uma forma próspera no futuro, eles possam escolher em qual deles querem viver.

\section{CONCLUSÃO}

Diante dos fatos apresentados, a educação infantil está se tornando cada vez mais importante na vida de bebês e crianças, ampliando todas as etapas do desenvolvimento, aprimorando e realizando as pesquisas necessárias, mostrando que essa etapa precisa ser respeitada e valorizada.

O processo formal de escrita antecede bebês e crianças dos centros de educação infantil, e eles possuem um aprendizado diferenciado, que é planejado pela gestão ativa no ensino pedagógico.

Muitas escolas têm discutido esse momento lúdico de leitura e contação de histórias e, por ser tão importante, é sabido que bebês e crianças podem registrar e entender os projetos apresentados pelos educadores, cada um à sua maneira.

Portanto, o incentivo à leitura e à contação de histórias nos centros de educação infantil faz parte da proposta pedagógica, pois todos ali estarão adquirindo o acesso de ler e escrever antes mesmo de ingressar no ensino fundamental.

Os momentos da roda de contação de histórias são acompanhados por aprendizagens culturais, sociais e étnicas, respeitando toda a diversidade que existe no seu meio, e sempre 
empenhados em trabalhar de forma significativa e conducente à formação humana cada vez mais ativa.

\section{REFERÊNCIAS}

BRASIL, Base Nacional Comum Curricular. Educação Infantil. Pacto Nacional pela Alfabetização na Idade Certa.

BRASIL, Referencial Curricular Nacional para Educação Infantil. Diretrizes Curriculares Nacionais para a Educação Infantil

BRESCIANE, Ana Lucia Antunes, Era uma vez para crianças pequenas, São Paulo: Revista Avisalá. Disponível em http://avisala.org.br. Acesso em 19/II/202I.

COUTINHO, Angela Maria Scalabrin. As relações sociais dos bebês na creche: em estudo numa perspectiva sociológica. Goiânia: Reunião Nacional da ANPED. Disponível em http://36reuniao/asrelacoessociaisdosbebesnacreche/umestudonumaperspectivasociologica. pdf. Acesso em I9/II/202I.

MATTOS, Maria Nazareth de Souza Salutto, Leitura literária na creche: o livro entre olhar, corpo e voz. Goiânia: Reunião Nacional da ANPED. Disponível em 2969 http://36reuniao/leituraliterarianacreche/olivroentreolharcorpoevoz. pdf. Acesso em I9/II/ 202I.

MINISTÉRIO da Educação, Secretaria de Educação Básica. Bebês como leitores e autores. Brasília. Disponível em http://www.projetoleituraescrita.com.br. Acesso em 29/II/202I.

VIGOTSKY. Pensamento e linguagem. São Paulo: Martins Fontes, 1989.

WALLON, Henri. Do ato ao pensamento. Petrópolis: Vozes, 2008. 